\title{
FUNÇÃO SOCIOAMBIENTAL DO DIREITO TRIBUTÁRIO
}

\author{
Francisleidi de Fátima Moura Nigra ${ }^{1}$ \\ Orientador Guilherme Gonçalves ${ }^{2}$
}

\section{RESUMO}

A Constituição Federal de 1988 ao fixar a questão ambiental e de desenvolvimento, de uma forma ampla foi rica em disposições, normas e princípios relativos à da dignidade da pessoa humana, qualidade de vida, bem-estar social, acesso ao trabalho, política do meio ambiente, política de desenvolvimento, política agrária, política tributária, dentre outros, assim, tais disposições são prescrições constitucionais que acabam por depender da efetivação através de políticas publicas. Ao abordar a questão relativa à tributação ambiental, devem ser levadas em consideração as propostas de Reforma Tributária que tramitam no Congresso Nacional, dessa maneira, o emprego do Imposto de Renda, do Imposto de Importação, do Imposto de Exportação, do Imposto sobre Produtos Industrializados, do Imposto sobre Circulação de Mercadorias e Serviços, do Imposto sobre Serviços, dentre outros, podem ter peculiaridades de impostos ambientais bem como, por exemplo, as taxas e demais contribuições tributárias.

Palavras-chave: Tributo; Meio Ambiente; Função Socioambiental; Direito Tributário; Reforma Tributária.

\section{ABSTRACT}

The Federal Constitution of 1988 to secure the environmental and development issue in a comprehensive way was rich in provisions, rules and principles aimed at the human dignity, quality of life, welfare, access to work, through policy environment, development policy, land policy, tax policy, among others, as well, such provisions are constitutional provisions which ultimately depend on the execution through public policies. In addressing the issue of environmental taxation, should be considered the proposals for tax reform that in the National Congress, in this way, the use of income tax, import tax, the Export Tax, the Tax on Industrialized Products, the tax on Goods and Services, tax Services, among others, may have environmental tax peculiarities as well as, for example, rates and other tax contributions.

Keywords: Tribute; Environment; Environmental Function; Tax Law; Tax Reform.

\footnotetext{
${ }^{1}$ Acadêmica do Curso de Pós Graduação em Direito do Estado da Universidade Estadual de Londrina.

${ }^{2}$ Curriculo acadêmico professor
} 


\section{INTRODUÇÃO}

O planejamento tributário pode ser considerado como se detalhar as alternativas que podem ser selecionadas dentro de uma determinada perspectiva temporal, levadas em consideração pela empresa como sendo de médio e longo prazo, quantificando-se analiticamente os recursos, volumes, preços, prazos, investimentos e demais variáveis planejadas.

O planejamento tributário é uma atividade preventiva que examina todos os atos e negócios jurídicos que o agente econômico pretende efetuar. O objetivo do planejamento é de obter a maior economia fiscal possível, diminuindo-se a carga tributária para o valor realmente devido por lei. A necessidade da atuação preventiva do operador do direito, no estudo das consequências fiscais dos negócios jurídicos que as pessoas pretendam praticar no mercado, não é mais do que uma realidade decorrente de todo o processo de dinamização das relações e investimentos que tenham relação aos fluxos de capitais, enfrentamento de concorrências sempre mais competitivas e da crescente complexidade do sistema tributário.

Com o conceito 'planejamento tributário' deve-se denominar a metodologia de composição preventiva de negócios, com intuito de instituir uma legal contenção de tributos, independendo de qualquer efeito dos atos efetuados. As atitudes lícitas que possam vir a ser utilizadas pelos contribuintes, na estruturação ou na reorganização de seus negócios, tendo como objetivo a economia de tributos, seja ao se coibir a incidência destes, seja reduzir ou diferir o respectivo impacto fiscal sobre as operações, corresponde à noção de legítima contenção de tributos.

Com certeza, pode haver planejamento tributário com conteúdo desonesto, porquanto o objetivo de economizar tributos pode ser atingida tanto por atos legítimos como por atitudes ilícitas do contribuinte. Por esse motivo, apenas, quando compostos os atos jurídicos esperados pelo sujeito ou averiguada sua omissão na composição dos fatos, por meio da linguagem competente, é que poderá o Fisco dominar a operação para revelar sua liceidade ou ilicitude e precisar se ocorreu evasão, elusão de tributos, simulação ou negócio indireto autêntico e adequado que acate a uma justa economia de tributos (elisão). 
Por esse ponto de vista, o planejamento tributário não é mais que uma técnica de "teste" preventivo que o operador faz do ordenamento, apreciando os fatos futuros à luz do ordenamento em vigor, numa projeção do ordenamento sobre os fatos posteriores. É um procedimento de subsunção antecipada, antevendo as consequências jurídico-tributárias, elaborada para o 'atuar' de acordo com o ordenamento, usando as operações menos onerosas disponíveis como legítimas. Seu conteúdo deverá considerar todas as repercussões do sistema, não somente a norma tributária estrita, aquela que designa a obrigação tributária principal, como também todas as obrigações possíveis: acessórias, penais, dentre outras.

Tanto o planejamento pode ter por objeto uma organização de atos lícitos, de acordo com o ordenamento, quanto pode dispor uma programação de atitudes, comissivas ou omissivas, com finalidades ilícitas, na pretensão de se minimizar a carga tributária. Presume-se que todas as operações estarão sendo postas em prática com efetiva idoneidade e que os negócios jurídicos serão válidos e regulares, com correta correspondência entre a forma e o conteúdo, porém, uma vez verificada a concretização dos atos planejados, abrem-se então as possibilidades para os atos de controle, não sobre o planejamento ou como sequela dele, mas, sobre os negócios jurídicos praticados efetivamente ou omissões derivadas.

Por esse motivo, ao Fisco não cabe dominar o planejamento tributário, mas sim, a consolidação dos atos condicionados pelas informações difundidas pelo planejamento, de tal sorte que somente após a concretização dos atos planejados é que os Estados poderão tomar medidas corretivas as posturas ilícitas perpetradas, segundo os graus sancionatórios típicos, mas, tudo dependerá da concretização dos atos planejados, por ação ou omissão.

Assim, o objetivo geral deste artigo é demonstrar que a extrafiscalidade é a melhor expressão de uma política de intervenção estatal na ordem socioeconômica, ou melhor, é um importante e eficiente meio de dirigismo social para atingir propósitos constitucionais, tendo como ênfase focar a questão da função socioambiental do Direito Tributário. Como objetivos específicos, pretende verificar se os incentivos fiscais estão inseridos no contexto intervencionista como instrumentos jurídico-tributários para concretizar o ideário extrafiscal e apontar se há que se dizer algo mais sobre incentivos fiscais, já que o tema está plantado num ambiente repleto de divergências doutrinárias, tanto em relação à falta de 
uniformidade na sua definição, quanto à complicada delimitação de sua natureza jurídica.

Para elaborar a revisão de literatura será adotada a metodologia de pesquisa bibliográfica. Pesquisa Bibliográfica é aquela fundamentada na apreciação da literatura já editada em forma de livros, periódicos, publicações avulsas, imprensa escrita e até eletronicamente, disponibilizada na Internet. No trabalho a ser elaborado, a revisão de literatura/pesquisa bibliográfica contribuirá para: obter informações sobre a situação atual do tema pesquisado; conhecer publicações existentes sobre o assunto e os aspectos que já foram tratados e examinar os julgamentos similares e diversos a respeito do assunto ou de aspectos relacionados ao tema da pesquisa.

\section{PLANEJAMENTO TRIBUTÁRIO E INCENTIVOS FISCAIS}

\subsection{O Meio Ambiente}

A ecologia está tornando-se alvo de atenções gerais. Os partidos políticos passaram a preocupar-se com seus efeitos e a incluir sua defesa como base de seus programas. Grupos ambientalistas começaram a apoiá-la, por vezes, com exagero cinematográfico. Já outros, em extremo oposto da mesma forma condenável, passaram a considerá-la como a razão de todos os problemas e a pregar reação total contra os seus defensores. Empresários, conscientes da importância do assunto, iniciaram debates a respeito e, até mesmo, estudos para conciliar o desenvolvimento e o equilíbrio ecológico (Sirvinskas, 2015, p. 27).

Segundo Freitas (2005, p. 14-15):

O conceito 'meio ambiente', adotado no Brasil, é criticada pelos estudiosos, porque meio e ambiente, no sentido enfocado, significam a mesma coisa. Logo, tal emprego importaria em grande redundância, onde na Itália e em Portugal usa-se, apenas, a uma palavra ambiente. O termo francês equivalente é milieu; o alemão é unwelt, o inglês, environment. Já na Espanha e países da chamada América espanhola usa-se a expressão entorno. No Brasil, empregase a expressão meio ambiente, apesar das divergências, por ser de uso consagrado no país. 
O termo 'ambiente' é, por essência, extremamente amplo, assim, antes de adentrar propriamente no estudo da expressão, é importante que, pode abrigar inúmeras realidades que se encontram na doutrina, para isso basta que se observe os conceitos dos autores que agem na área ambiental. $O$ conceito de 'meio ambiente' é novel, assim, como a gestão do meio ambiente constitui uma atividade também recente. Até poucos anos atrás, os recursos ambientais eram abordados de forma isolada no país, motivo pelo qual os instrumentos e os mecanismos relevantes à gestão do meio ambiente ainda não estavam desenvolvidos e aperfeiçoados em sua plenitude (Sirvinskas, 2015, p. 28).

Pontua-se que meio ambiente é unitário, na medida que é regido por inúmeros princípios, diretrizes e objetivos que compõem a Política Nacional do Meio Ambiente - PNMA (Lei n. 6.938, de 31 de agosto de 1981).

Nas palavras de Sirvinskas (2015, p. 28):

O termo meio ambiente é muito criticado pela doutrina, pois meio é tudo aquilo que está no centro de alguma coisa. Ambiente indica o lugar ou a área onde habitam seres vivos. Assim, na palavra "ambiente" está também inserido o conceito de meio. Cuida-se de um vício de linguagem conhecido por pleonasmo, consistente na repetição de palavras ou de idéias com 0 mesmo sentido simplesmente para dar ênfase. Resumindo, o meio ambiente é o lugar onde habitam os seres vivos.

Freitas (2005, p. 15) cita que:

O conceito 'meio ambiente' já está consagrado na legislação, na doutrina, na jurisprudência e na consciência da população, assim, entende-se por meio ambiente: o conjunto de condições, leis, influências, alterações e interações de ordem física, química e biológica, que possibilita, abriga e rege a vida em toda as suas formas (art. 3o, I, da Lei n. 6.938/81). Registre-se que o conceito legal de meio ambiente não é adequado, pois não abrange de maneira ampla todos os bens jurídicos protegidos. É um conceito restrito ao meio ambiente natural.

Nos dias atuais, o conceito jurídico mais usual de meio ambiente pode-se distinguir duas perspectivas principais: uma estrita e outra ampla. Numa visão estrita, o meio ambiente nada mais é do que a expressão do patrimônio natural e as relações entre os seres vivos. Numa visão ampla, que vai além dos limites estreitos fixados pela ecologia tradicional, o meio ambiente abrange toda a natureza original e artificial, assim como os bens culturais correlatos. 
A definição legal não levou em consideração as inúmeras controvérsias dos cientistas no que diz respeito o alcance da expressão meio ambiente, porém, serviu ao propósito de restringir-se o conceito no campo jurídico.

Silva (2013, p. 2) conceitua meio ambiente como sendo "a interação do conjunto de elementos naturais, artificiais e culturais que propiciem 0 desenvolvimento equilibrado da vida em todas as suas formas". Para completar esse conceito, acrescenta-se também o meio ambiente do trabalho.

Importante socorrer-se de Rocha (2001, p. 27), que assim aborda a expressão 'meio ambiente':

Partindo-se dessa conceituação doutrinária, pode-se dividir o meio ambiente em: meio ambiente natural - engloba a atmosfera, as águas interiores, superficiais e subterrâneas, os estuários, o mar territorial, o solo, o subsolo, os elementos da biosfera, a fauna, a flora, o patrimônio genético e a zona costeira (art. 225 da CF); meio ambiente cultural - engloba os bens de natureza material e imaterial, os conjuntos urbanos e sítios de valor histórico, paisagístico, artístico, arqueológico, paleontológico, ecológico e científico (arts. 215 e 216 da CF); meio ambiente artificial - engloba os equipamentos urbanos, os edifícios comunitários (arquivo, registro, biblioteca, pinacoteca, museu e instalação científica ou similar) (arts. 21, XX, 182 e s. e 225 da CF); e meio ambiente do trabalho - engloba a proteção do homem em seu local de trabalho, com observância às normas de segurança (arts. 200, VII e VIII, e 7으, XXII, ambos da CF).

Ferreira (1995, p. 29) entende meio ambiente apenas como:

A integração do patrimônio nacional brasileiro (art. 215, caput, c/c o art. 225, caput, da CF), que se divide em: patrimônio natural e patrimônio cultural, pois nem todo o patrimônio artificial é protegido por lei, ato administrativo ou decisão judicial. Só o será se possuir valor histórico, cultural, científico, turístico etc.

Transforma-se, desse modo, o meio ambiente artificial em patrimônio cultural e o meio ambiente do trabalho em patrimônio natural, bastando, portanto, essa divisão, assim, adota-se a classificação de meio ambiente: natural, cultural, artificial e do trabalho. Trata-se de uma classificação didática e útil para a compreensão dos seus conceitos, pois, com essa abordagem é que se pode compreender o preceito constitucional e as normas de proteção ambiental que visam proteger a sadia qualidade de vida dos seres vivos. 
As normas de proteção ao meio ambiente acabam por partir do conflito de interesses gerados nas relações do homem com a natureza e do homem com os processos produtivos, refletindo-se em todas as demais ações sociais, estando à questão ambiental envolvida com o cerne da conflituosidade da sociedade moderna (Fiorillo, 1999, p. 32).

Para amparar essa questão, emergiu um ramo específico do direito denominado Direito Ambiental. Uma grande parte dos doutrinadores consagrados como estudiosos sobre o tema, dizem que primeiramente deve-se partir dos princípios norteadores da ciência, pois só assim será atingido o alvo que é a preservação de todas as espécies existentes no planeta.

\subsection{Norma Jurídica e Norma Tributária}

A norma jurídica, na acepção de regra de conduta, é o único meio eficaz de controle do comportamento humano, já que esta correlaciona e ordena o aglomerado de deveres centrípetos que levam ao but social, bem como o feixe de direitos centrífugos que daí partem e desta relação ativa entre deveres e direitos, em prol do bem comum, que se ocupa o Direito. A doutrina majoritária elege o trabalho de Carvalho (2014, p. 55) como o mais profundo no campo do estudo da norma jurídica em geral e a norma jurídica tributária em especial.

Young (2014, p. 61) diz que:

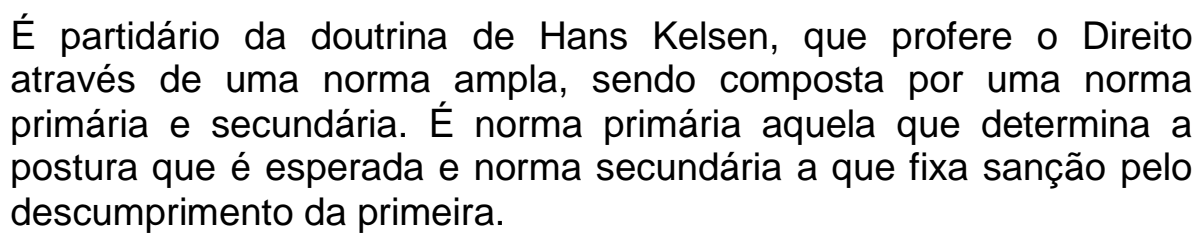

Cossio adota outra classificação e terminologia, de "perinorma" como norma primária e "endonorma" como secundária e é esta a terminologia que prefere o professor Carvalho (2014, p. 56).

Ainda segundo Carvalho (2014, p. 56):

Tanto as normas primárias como as secundárias apresentam igual estrutura lógica: uma hipótese e uma consequência, unidas pelo 
conectivo do dever ser (sollen). A associação é metaforicamente definida como sendo uma "cópula deôntica", mas, a atuação dinâmica da norma jurídica é a fenomenologia da incidência, que tem amiúde sido negligenciada no Direito Tributário.

Pode-se verificar que distingue-se a norma jurídica dos textos que constituem o Direito Positivo. As leis não fornecem as normas jurídicas prontas e finalizadas, com uma simples percepção e isso ocorre por diversas razões: a linguagem híbrida do legislador, a heterogeneidade dos parlamentos, a democracia como fator de mesclagem parlamentar etc. (Young, 2014, p. 61-62).

Para se conhecer a estrutura da norma jurídica tributária é mister conhecer profundamente a estrutura da norma jurídica em si. A qualificação da norma jurídica tributária pode seguir a vários critérios, e nesse trabalho escolhe-se em concordância com a doutrina majoritária, o critério do grupo institucional a que pertence, isto é, norma jurídica tributária que define princípios, norma jurídica tributária que delimita a incidência tributária e norma jurídica tributária que estabelece providências administrativas (Young, 2014, p. 62).

Segundo Carvalho (2014, p. 23), deve-se denominar-se de "norma jurídica tributária" em sentido estrito a regra-matriz de incidência tributária e todas as demais de normas jurídicas tributárias em sentido amplo. A legislação pátria, como menciona Young (2014, p. 62), "acabou por abrir as portas ao fato gerador de Gaston Jèse, e o fez mal por sua equivocidade flagrante".

O fato gerador se refere à abstração da descrição do fato e concretização do próprio evento no mundo fático, sendo que mais acurada terminologia seria "hipótese de incidência tributária" e "fato jurídico tributário". Os critérios da hipótese de incidência tributária são: critério material (verbo e complemento), critério espacial e temporal. No critério material há uma referência a um comportamento de pessoas, físicas ou jurídicas, condicionado por circunstâncias de espaço e tempo, deve-se abstrair os condicionantes espaço - temporais para analisá-lo de modo particular (Young, 2014, p. 62).

Os doutrinadores amiúde cometem o erro de confundir o núcleo da hipótese normativa com a própria hipótese, definindo a parte pelo todo. O núcleo ora referido é um verbo (que exprima ação) mais um complemento, já que é aludido a um comportamento humano (Young, 2014, 62-63). 
Berti e Berti (2016, p. 13) ressaltam que a classificação do gênero tributo na conformidade com o critério espacial da hipótese tributária pode dar-se de inúmeros modos:

- Hipótese que faça uma menção a um determinado local para a ocorrência do fato típico;

- Hipótese que aluda às áreas consideradas específicas e somente nelas pode o fato típico ocorrer;

- Hipótese genérica, onde todo e qualquer fato, que ocorra na vigência territorial da lei, produz efeitos particulares.

É oportuno lembrar que o critério espacial da norma jurídica tributária não se confunde com o campo de validade da lei. O critério temporal configura-se como - grupo de indicações que oferece elementos para saber em que preciso instante ocorre o fato descrito, passando a existir o liame jurídico entre devedor e credor, em função do objeto (Berti e Berti (2016, p. 14).

A distinção dos fatos geradores entre instantâneos, continuados e "complexivos" merece algumas críticas de Carvalho (1981, p. 530). O autor considera todos os fatos geradores instantâneos, sustentando que o acontecimento só gera efeitos fiscais no instante em que todos os fatos conjugados estejam plenamente concretizados.

Ainda segundo Carvalho (1981, p. 530):

Os fatos geradores - segundo a mais tradicional doutrina - são instantâneos quando se esgotam em determinado tempo, dando origem a uma obrigação tributária autônoma. São continuados se configuram situações duradouras, e "complexivos" se sua formação tiver implemento com o transcurso do tempo, integrando-se vários fatores para o surgimento do fato final.

Fixados os critérios da hipótese de incidência tributária, deve-se dirigir a análise para a consequência tributária, esta composta pelos critérios pessoal (sujeito ativo e passivo) e quantitativo (base de cálculo e alíquota). Deve-se discernir entre a consequência tributária e a relação jurídica tributária específica, aquela como uma prescrição genérica desta e este vínculo jurídico individualizado. A doutrina dominante antevê a relação jurídica tributária com caráter patrimonial (Berti e Berti, 2016, p. 14). 
Adotando a classificação das relações jurídicas em obrigacionais (de natureza patrimonial) e não obrigacionais (de cunho diverso), se pode discriminar as relações jurídicas tributárias em obrigações tributárias (com caráter patrimonial) e deveres instrumentais e formais. Os deveres tributários são erroneamente denominados pelo Código Tributário Nacional ${ }^{3}$ de obrigações acessórias, mas, não são obrigações (não têm natureza patrimonial) nem acessórias (porque muitas vezes independem das principais).

De acordo com Berti e Betrti (2016, p. 15):

O sujeito ativo é o titular do direito subjetivo de exigir a prestação pecuniária, assim, no direito nacional pode ser uma pessoa jurídica pública ou privada. Pode ser pessoa física, se desempenhar, em determinado momento, atividade exclusiva de real interesse público. Há mandamentos da Constituição Federal de 1988 que permitem aos titulares de competência tributária a transferência da capacidade ativa, nomeando outro ente, seja público ou privado. Já o sujeito passivo é pessoa física ou jurídica, privada ou pública, sujeito de dever de quem se exige o cumprimento da prestação pecuniária ou de deveres instrumentais ou formais. O Estado tem interesse ou necessidade de cobrar tributos de pessoa diversa: dá-se a sujeição passiva indireta. Apresenta duas modalidades: substituição e transferência; a última comporta três hipóteses (solidariedade, sucessão e responsabilidade).

Finalmente, é importante investigar o critério quantitativo, composto da base de cálculo e alíquota. O grupo de informações que o intérprete extrai dos textos legais, e que permite precisar, a quantia devida a título de tributo é o que chamamos de critério quantitativo. É explícito pela conjugação de duas entidades: base de cálculo e alíquota (Carvalho, 2014, p. 160).

Carvalho (2014, p. 160) associa, sutilmente, a base de cálculo ao critério material da hipótese tributária. A base de cálculo deve dimensionar a intensidade do comportamento, confirmando, afirmando ou até mesmo infirmando o critério material. Tem três funções distintas:

1. Medir as proporções reais do fato;

2. Compor a específica determinação da dívida;

3. Confirmar, infirmar ou afirmar o real critério material da hipótese tributária.

\footnotetext{
${ }^{3}$ BRASIL. Código Tributário Nacional: Lei 5.172, de 25 de outubro de 1966. 2.ed. São Paulo: Saraiva, 1997.
} 
Entende-se que congregada à base de cálculo, a alíquota dá a compostura numérica da dívida, gerando o valor que pode ser requerido pelo sujeito ativo, em cumprimento da obrigação que nascera pelo acontecimento do fato típico. De forma etimológica, alíquota significa parcela, sendo assim, a doutrina insiste em entendê-la como sendo a quota que o Estado chama para si, da base de cálculo que é manifestada pelo fato jurídico tributário (Carvalho, 2014, p. 160).

\subsection{Contribuintes e Responsáveis na Obrigação Tributária}

Segundo o art. 121 do CTN, a pessoa incumbida de cumprir o dever jurídico de natureza tributária denomina-se sujeito passivo. Este, de seu turno, desdobra-se em contribuinte, quando realiza o fato jurídico tributário, ou responsável, quando, mesmo não praticando o fato jurídico, assume a condição de sujeito passivo por força de lei (Jardim, 2005, p. 25).

Quando a lei escolhe como sujeito passivo ao indivíduo que realiza o fato gerador, esse sujeito passivo recebe denominação de contribuinte, que, como regra, é aquele que pratica o fato gerador do tributo e se encontra tal conceituação no art. 150, § $7^{0}$ da Constituição Federal de 1988 (Gubert, 2003, p. 28).

$\mathrm{O}$ art. 121 do CTN traz o conceito de sujeito passivo, o qual engloba o contribuinte e o responsável:

\footnotetext{
Art. 121. Sujeito passivo da obrigação principal é ao individuo obrigado ao pagamento de tributo ou penalidade pecuniária.

Parágrafo único. O sujeito passivo da obrigação principal diz-se: I - contribuinte, quando tenha relacionamento pessoal e direto com a situação que constitua o respectivo fato gerador;

II - responsável, quando, sem revestir a condição de contribuinte, sua obrigação decorra de disposição expressa de lei.
}

Existe plena conceituação de contribuinte em nosso ordenamento jurídico, não deixando pairar qualquer dúvida quanto ao sujeito passivo da obrigação, assim, o legislador pode eleger como sujeito passivo um terceiro, isto é, não aquele que realiza o fato gerador do tributo. Em outras palavras, ocorre uma substituição tributária, visto que a lei substitui ao indivíduo que deveria ser o contribuinte por um outro indivíduo (terceiro) (Goubert, 2003, p. 28). 
Observar que há uma diferenciação entre o responsável previsto no inc. II do parágrafo único do art. 121 e o responsável do art. 128, ambos do CTN, sendo que o primeiro está identificado na norma, sendo responsável pela obrigação própria, porém, o segundo, não está identificado na norma de incidência, sendo responsável pela obrigação de outro indivíduo (Goubert, 2003, p. 28-29).

A responsabilidade de terceiros, exposta no art. 134 do CTN, define que, se não for possível exigir que o contribuinte cumpra a obrigação principal, serão solidariamente responsáveis com este, nos atos em que intervierem, ou pelas omissões que cometerem: os pais, os tutores, os curadores, os administradores de bens de terceiro, o inventariante, o síndico, o comissário, os tabeliães, os escrivães, os sócios, na liquidação de sociedades de pessoas. Lembrar que em relação às penalidades, só se aplicam as de caráter moratório (Goubert, 2003, p. 29).

No caso de responsabilidade de terceiros, prevista no art. 135 do CTN, as pessoas acima citadas, bem como os mandatários, prepostos e empregados, os diretores e sócios-gerentes são pessoalmente responsáveis pelo crédito tributário correspondente às obrigações tributárias advindas de atos realizados com excesso de poderes ou infração de lei, estatuto ou contrato social (Goubert, 2003, p. 29).

$\mathrm{O}$ art. 136 do CTN define que a responsabilidade por infrações da legislação tributária independe do intuito do agente ou do responsável e da efetividade, natureza e extensão dos efeitos do ato (Goubert, 2003, p. 30).

De acordo com o art. 137 do CTN, a responsabilidade é considerada pessoal ao agente:

I - quanto às infrações conceituadas por lei como crimes ou contravenções, exceto quando realizadas no exercício regular de administração, mandato, função, cargo ou emprego, ou cumprimento de ordem expressa emitida por quem de direito;

II - quanto às infrações em cuja definição o dolo peculiar do agente seja elementar;

III - quanto às infrações que derivam direta e exclusivamente de dolo específico, a responsabilidade é pessoal:

a) das pessoas referidas no art. 134, contra aquelas por quem respondem;

b) dos mandatários, prepostos ou empregados, contra seus mandantes, preponentes ou empregadores;

c) dos diretores, gerentes ou representantes de pessoas jurídicas de direito privado, contra estas. 
$\mathrm{Na}$ dicção do art. 121, parágrafo único, inc. II, do CTN, se têm: "responsável, quando sem revestir a condição de contribuinte, sua obrigação decorra de disposição expressa de lei”, nesse sentido, Fabretti (2005, p. 74) procura ressaltar que:

O responsável não arca com o ônus tributário, que é suportado pelo contribuinte de fato. Age como uma espécie de agente arrecadador do Fisco e como seu depositário. Cabe-Ihe recolher as importâncias descontadas ou cobradas do contribuinte de fato, ao Fisco, nos prazos da lei. Não o fazendo, será declarado depositário infiel, sujeito à pena de prisão (Lei n. 8.866/94).

Conforme define o art. 146 do Regulamento do Imposto de Renda RIR/99 (Decreto n. 3.000/99), são contribuintes do imposto e terão seus lucros apurados de conformidade com este Decreto:

I - as pessoas jurídicas;

II - as empresas individuais.

Tem supedâneo no art. 45 do CTN, que dispõe a titularidade de contribuinte do imposto, da competência da União, relativamente à renda e proventos de qualquer natureza, tendo como fato gerador à aquisição da disponibilidade econômica ou jurídica, de renda (produto oriundo do capital, do trabalho ou da combinação de ambos) e de proventos de qualquer natureza (acréscimos patrimoniais) (Fabretti, 2005, p. 74).

\subsection{Conceituação de Isenção Fiscal}

Nabais (2012, p. 390-391), baseado no Estatuto dos Benefícios Fiscais e na Lei Geral Tributária portugueses, faz uma distinção entre os benefícios e os incentivos fiscais. O autor classifica os benefícios fiscais (lato sensu) em duas modalidades essenciais:

Benefícios fiscais estáticos (stricto sensu) e benefícios fiscais dinâmicos (incentivos ou estímulos fiscais). Aqueles não visam, pelo menos diretamente, incentivar ou estimular, mas apenas beneficiar por razões de política geral de defesa econômica, social, cultural, religiosa etc., ou seja, a causa do benefício é a situação beneficiada em si mesma. Estes, os benefícios fiscais dinâmicos, por outro lado, 
visam estimular determinadas atividades, são altamente seletivos, têm caráter temporário e possuem como causa a adoção de um comportamento futuro pelo beneficiado.

Apesar de reconhecer a coerência da distinção entre incentivos e benefícios fiscais realizada no plano do direito positivo e da ciência do direito português, deve-se ter cautela ao tentar importá-la para o contexto jurídico brasileiro. Em primeiro lugar, é necessário salientar que em Portugal os benefícios fiscais estão submetidos ao regime jurídico do direito econômico; no Brasil, por outro lado, como será demonstrado mais à frente, os incentivos fiscais não estão submetidos a um regime jurídico único. Em segundo lugar, no Brasil, em regra, não se costuma fazer distinção entre as expressões "benefícios fiscais" e "incentivos fiscais" (Oliveira Júnior, 2016, p. 58).

O próprio texto constitucional, quando as cita expressamente, não faz diferenciações para regular o procedimento de concessão e de revogação, ou quando demarca os limites constitucionais ao exercício da competência exonerativa dos entes federativos (Grupenmacher, 2012, p. 17-18).

Como observa Correia Neto (2014, p. 36), "na Constituição Federal de 1988 e também na legislação infraconstitucional, as expressões 'benefícios' e 'incentivos fiscais' são sinônimas, perfeitamente intercambiáveis”. No que concerne à definição dos incentivos fiscais, esta parece ser uma tarefa árdua e complexa, já que a doutrina nacional não é uníssona acerca da matéria, assim, Pires (2007, p. 19) destaca que "qualquer fórmula que reúna características genéricas do tema poderá inibir a identificação de desvios ou de fins antijurídicos ou ilegítimos ocultos".

Catão (2004, p. 13), definiu incentivos fiscais como:

São instrumentos de desoneração tributária, aprovados pelo próprio ente político autorizado à instituição do tributo, através de veículo legislativo específico, com o propósito de estimular o surgimento de relações jurídicas de cunho econômico. Trata-se de uma suspensão parcial ou total, mas sempre provisória, do poder que lhe é inerente, a fim de conformar determinadas situações, diferindo a tributação para o momento em que a captação de riquezas (imposição fiscal) possa ser efetuada de maneira mais efetiva, eficiente e justa.

Nota-se uma certa imprecisão na definição apresentada pelo autor, já que este o restringe à desoneração de carga fiscal, isto é, não leva em consideração a 
existência de outros incentivos, de natureza tributária, que autorizam, por exemplo, a adoção de sistemática diferenciada de recolhimento de tributos ou que simplificam o cumprimento de deveres instrumentais (Oliveira Júnior, 2016, p. 60).

Catão (2004, p. 14) elenca como elemento característico:

\begin{abstract}
A suspensão provisória do poder tributar. Não obstante, os incentivos fiscais estão inseridos no campo da extrafiscalidade, e esta, por sua vez, é caracterizada como o exercício do poder de tributar para intervir na ordem socioeconômica, na busca de atingir objetivos constitucionais diferentes do arrecadatórios. Não há efetivamente uma suspensão do poder de tributar, pelo contrário, o ente tributante o exerce para atingir outra finalidade: ecológica, econômica, redução de desigualdades regionais etc.
\end{abstract}

Como anota Carvalho (2013, p. 162), "a mesma mão que cobra o tributo concede o benefício" ou a simetria entre o poder de tributar e o de isentar é perfeita. A definição traz ainda como elemento característico o diferimento da tributação para momento futuro, porém, deve ser lembrado que há benefícios fiscais cujo motivo que fundamenta a não tributação é a própria condição de incapacidade econômica do contribuinte, de modo que não haverá, nesse caso, um diferimento da tributação para o futuro, mas, sim uma isenção, uma redução na base de cálculo ou uma remissão, por exemplo, ou seja, o tributo não é pago nem no presente nem no futuro.

\title{
2.5 Regime Jurídico dos Incentivos Fiscais
}

Não há um instrumento normativo específico, no plano do direito positivo brasileiro, que trate dos incentivos fiscais, embora estes sejam reconhecidos expressamente no nível constitucional, assim como no plano legal. O ponto de partida para delimitar o regime jurídico dos incentivos fiscais será o texto constitucional, as disposições infra-constitucionais que tratam especificamente da matéria, assim como a doutrina jurídica (Oliveira Júnior, 2016, p. 62).

Existem na Constituição Federal, diversas passagens que autorizam expressamente o exercício de competência para a concessão de incentivos fiscais. Podem ser citadas, por exemplo, a autorização para promover o equilíbrio socioeconômico entre as diferentes regiões brasileiras, para concessão de tratamento tributário de adequado às cooperativas, para intervir na economia, para 
incentivar o desenvolvimento científico e o desenvolvimento cultural etc. Enfim, são diversos os dispositivos que fundamentam a concessão de benefícios fiscais no âmbito de atuação dos entes federativos (Oliveira Júnior, 2016, p. 62).

Da análise do texto constitucional, não se vislumbra uma sistematização sobre a matéria de modo que se possa demarcar o regime jurídico a que está submetido o ente competente para incentivar, fomentar ou beneficiar o contribuinte. O Código Tributário Nacional também não trouxe normas gerais que prescrevam enunciados uniformizadores, como diferentemente o fez para os institutos da prescrição, da decadência, da anistia e da isenção, por exemplo. Apesar disso, a demarcação da natureza jurídica dos incentivos fiscais pode e deve partir da análise da Constituição Federal (Oliveira Júnior, 2016, p. 63).

Como nos explica Borges (2000, p. 85), "é o ordenamento constitucional quem corrobora, na hipótese, as proposições doutrinárias, possibilitando confirmar, a partir dos preceitos constitucionais pertinentes, o regime jurídico aplicável às respectivas categorias normativas".

A Constituição Federal de 1988, no seu art. 24, I, distingue formalmente o direito tributário e o direito financeiro quando os enuncia em apartado nesse preceito. Quer dizer, as normas gerais de direito financeiro e as de direito tributário têm diferentes regimes jurídicos de natureza material (matéria regulada), embora tenham idêntico regime jurídico de natureza formal ou procedimental (art. 69, CF), isto é, estão submetidos à reserva de lei complementar (Borges, 2000, p. 89).

Parte da doutrina brasileira adota critério de classificação baseado na órbita de atuação dos incentivos fiscais (direito tributário ou direito financeiro), considerando fator essencial para essa demarcação o momento em que ocorre a extinção do crédito tributário. Os incentivos fiscal-tributários implicam a exclusão total ou parcial do tributo antes da extinção do crédito, ou seja, estão no âmbito das receitas públicas; os incentivos fiscal-financeiros são concedidos após a extinção do crédito e estão relacionados com as despesas públicas (Pires, 2007, p. 20).

Essa distinção é de extrema utilidade prática e teórica. Primeiro, porque a eleição de uma dessas duas modalidades, quando da criação de uma política fiscal de incentivos, repercutirá também na escolha de um regime jurídico específico, cujas normas jurídicas são também particulares, que devem ser observadas sob pena de inconstitucionalidade da política incentivadora. Já em segundo lugar, a distinção facilita até mesmo a identificação de simulações, fraudes ou de qualquer outra 
fórmula ardilosa que possibilite o desvio de recursos públicos para o setor privado (Peixoto, 2007, p. 79).

Por fim, pode-se dizer que, quando o Estado incentiva a atividade do particular, manejando a norma jurídica tributária, atua na esfera do direito tributário, concedendo incentivos de natureza tributária (incentivos fiscal-tributários); por outro lado, quando direciona despesas públicas para atender a iniciativa privada, atua na esfera do direito financeiro e também concede incentivos de natureza financeira (incentivos fiscal-financeiros) (Borges, 1998, p. 118).

\subsection{As Funções Fiscal, Parafiscal e Extrafiscal}

Dentre outras perspectivas, o direito também é visto como um instrumento de regulação de condutas intersubjetivas. Mediante a sua juridicização o Estado impõe aos destinatários comportamentos positivos, negativos ou permissivos, em vista a atender determinadas finalidades. Normas jurídicas têm funções e finalidades, um campo ainda pouco estudado pela ciência do direito (Borges, 2007, p. 377).

Para Harada (2005, p. 309-310):

Tradicionalmente o direito tributário é um instrumento que tem servido ao Estado para garantir os ingressos financeiros, com os quais o mesmo faz frente ao pagamento de suas despesas. Esse subsistema passou a ganhar maior destaque a partir do momento em que a administração pública percebeu que era mais vantajoso arrecadar em espécie a confiscar o patrimônio de seus súditos. Com o passar do tempo, aperfeiçoou-se este poderoso instrumento de obtenção de ingressos financeiros.

Abastecer o erário não é a única finalidade da tributação, pois, esta pode ser utilizada para atender a outras finalidades estatais. A esse fenômeno, de utilização da tributação com fins diversos do arrecadatório, se atribuiu o nome de função extrafiscal do tributo. Fiscalidade, extrafiscalidade e parafiscalidade representam metas a serem alcançados pela ação estatal de impor tributos, assim, trata-se de uma classificação, no qual o critério é a finalidade da tributação: tributação instituída para arrecadar; induzir condutas (positiva ou negativamente); ou 
abastecer de recursos entidade da Administração Pública indireta ou paraestatal (Carvalho, 2012, p. 289-290).

Schoueri (2005, p. 32-33), por sua vez, apresenta proposta distinta ao classificar a finalidade da norma tributária, assim, diz que:

As normas tributárias teriam função simplificadora, extrafiscal (divididas entre as extrafiscais em sentido estrito e as de política social) e as normas de função fiscal. A extrafiscalidade, que está ao lado das funções simplificadora e fiscal, é gênero, das quais são espécies a norma indutora (extrafiscalidade em sentido estrito) e as normas de política social: O gênero 'extrafiscalidade' inclui os casos não vinculados nem à distribuição eqüitativa da carga tributária, nem à simplificação do sistema tributário.

A tributação extrafiscal é aquela orientada para fins outros que não a captação de dinheiro para o Erário, tais como a redistribuição de renda e da terra, a defesa da indústria nacional, a orientação dos investimentos para setores produtivos ou mais adequados ao interesse público, a promoção do desenvolvimento regional ou setorial etc. (Schoueri, 2005, 32-33).

Inclui, neste sentido, além de normas com função indutora (que seria a extrafiscalidade em sentido estrito, como se verá abaixo), outras que também se move por razões não fiscais, mas, desvinculadas da busca do impulsionamento econômico por parte do Estado (Schoueri, 2005, 33).

Carvalho (2014, p. 291) ressalta que:

A classificação que toma por objeto a finalidade da tributação é realizada a partir da prevalência de uma função sobre a outra, em um determinado tributo. Por mais que determinadas espécies tributárias tenham maior aptidão fiscal ou extrafiscal, por exemplo, nenhuma espécie será pura. Não existe entidade tributária que se possa dizer pura, no sentido de realizar tão só a fiscalidade, ou, unicamente, a extrafiscalidade. Os dois objetivos convivem, harmônicos, na mesma figura impositiva, sendo apenas lícito verificar que, por vezes, um predomina sobre o outro.

Fiscal é o tributo cuja função é arrecadar. Parafiscal é o tributo cuja função é abastecer os cofres de entidades da Administração Pública indireta ou paraestatal, para que elas possam cumprir seu mister. Por fim, extrafiscal é o tributo cuja função é diversa da arrecadatória. Essa classificação, como dito, leva em conta a finalidade 
do tributo e é vista, por parte da doutrina do direito tributário, como matéria da ciência das finanças (Saliba, 2005, p. 271).

É difícil conceber o uso do direito, assim como seu efeito, como algo totalmente alheio ao próprio direito. A criação do direito é um fenômeno jurídico, que se realiza de acordo com as normas de competência, conforme já destacado quando abordado o suposto fechamento sintático do sistema jurídico. A finalidade do tributo também é um tema do direito tributário (Machado, 2004, p. 79).

Segundo Ricci (2015, p. 46):

O tributo será fiscal, parafiscal ou extrafiscal conforme sua organização jurídica desvendar finalidade de arrecadar, de abastecer de receita tributária pessoa jurídica distinta do ente político que instituiu o tributo, ou quando tiver por fim objetivo distinto da arrecadação, como a orientação de condutas ambientalmente adequadas, por exemplo.

O aumento de um tributo visando desestimular conduta não pode ser tomado como um fenômeno fora do jurídico. Pelo contrário, a criação de tributo é fortemente regulada pela Constituição de 1988 e se insere no âmbito das normas de competência. Ocorre que as normas de competência trazem para o universo jurídico os conceitos de outros subsistemas sociais. Talvez, por isso, parte da doutrina tributária coloque a função do tributo fora do contexto jurídico (Ricci, 2015, p. 46).

\subsection{Função Socioambiental do Direito Tributário}

Para se implementar o objetivo de equalizar desenvolvimento econômico e preservação ambiental, idealizou-se um Estado de direito ambiental, que, no Brasil, projetou-se com o advento da Constituição Federal de 1988, que reconheceu o bem ambiental como sendo "equilíbrio ecológico do meio ambiente" (Leite e Canotilho, 2007, p. 433).

A proteção do meio ambiente é tamanha que acaba revelando uma relação intertemporal, conforme diz Derani (2008, p. 112). A geração atual tem o dever, portanto, de proteger o meio ambiente para as gerações futuras. A própria Constituição reconhece ser o meio ambiente "bem de uso comum do povo e essencial à sadia qualidade de vida". 
Daí o imperioso anseio de sua proteção, a qual, igualmente, foi reconhecida pela Constituição, na medida em que impõe "ao Poder Público e à coletividade o dever de defendê-lo e preservá-lo para as presentes e também as futuras gerações" (Ricci, 2015, p. 66).

O direito tributário é uma das ferramentas de atuação nas externalidades resultantes das atividades privadas que, embora "privadas", acabam gerando repercussões, positivas e negativas, sentidas pela coletividade em geral. Daí falar-se em 'externalidades', pois, são consequências, positivas ou negativas, que repercutem na esfera jurídica de sujeitos que não participaram do ato desencadeador (Braga e Castro, 2009, p. 179-180).

Segundo Cristiane Derani (2005, p. 648):

No decorrer do processo produtivo, além do produto a ser comercializado, são produzidas "externalidades negativas". São chamadas externalidades porque, embora resultante da produção, são recebidas pela coletividade, ao contrário do lucro, que é percebido pelo produtor privado. Daí a expressão 'privatização de lucros e socialização de perdas', quando identificadas as externalidades negativas. Com o uso do princípio do poluidorpagador, procura-se corrigir este custo adicionado à sociedade, impondo-se sua internalização, por isto, este princípio também é conhecido como o 'princípio da responsabilidade'.

Quanto às externalidades negativas, a tributação ambiental seria um meio de internalização dos custos. Nesse caso, o direito tributário serviria como um instrumento de concretização de políticas de proteção ambiental, por alterar a equação de custo-benefício, que certamente é levada em conta pelos agentes econômicos potencialmente poluidores, assim, como pelos consumidores (Ferraz, 2005, p. 341).

No caso das externalidades positivas, a tributação ambiental recompensaria seu gerador, mediante, por exemplo, creditamentos fiscais relativos a insumos ambientalmente adequados, assim como, por exemplo, a máquinas e equipamentos que minimizem o impacto ambiental ou reduzam a emissão de poluentes (Ricci, 2015, p. 67).

Por meio da instituição de tributos, majoração ou diminuição de alíquotas de tributos já existentes, ou da criação de outros benefícios fiscais, dentre outras possibilidades, é possível influenciar na decisão econômica, de modo a tornar mais interessantes as opções ecologicamente adequadas. 
A alteração na fórmula dos custos dos bens e serviços, mediante imposição tributária, certamente reflete em seu preço final, fazendo com que a tributação ambiental sirva para o estímulo ao consumo ambientalmente adequado (Ricci, 2015, p. 68).

O direito tributário tem o potencial de servir ao meio ambiente em suas múltiplas funções: fiscal, extrafiscal e parafiscal. Fiscal, abastecendo o erário para o desempenho de programas ambientais. Extrafiscal, estimulando ou desestimulando posturas dos contribuintes e dos consumidores, a fim de que estes tomem decisões ambientalmente mais adequadas. E parafiscal, abastecendo os cofres de instituições da Administração Pública indireta, ou mesmo paraestatais, para a realização de projetos ambientais.

A dificuldade na utilização de qualquer das espécies, notadamente no caso dos impostos, é compatibilizar a imperiosa necessidade de proteção do bem ambiental, ao rígido sistema constitucional tributário. Daí a relevância da investigação a respeito dos limites para a referida tributação ambiental. Em suma, o bem ambiental é reconhecidamente um dos mais valiosos bem jurídicos, mas, sob tal bandeira, se permite tudo em matéria tributária? Se o direito tributário tem potencial para ser relevante instrumento de políticas públicas e se o bem ambiental é bem jurídico cuja proteção deva ser efetivada pelas mais variadas formas, é vital pesquisar os limites à utilização ambiental dos tributos (Freitas, 2005, p. 23).

Trata-se de uma relação entre meio e fim, ou seja, como o direito tributário (meio) pode servir de instrumento de proteção ao bem ambiental (fim) que, igualmente, é direito e garantia fundamental constitucionalmente reconhecido, como escreve Freitas (2005, p. 23):

Atualmente, no Brasil, é o direito a um meio ambiente sadio reconhecido como direito fundamental do cidadão. É verdade que ele não está incluído no rol previsto no art. 5ำ da Constituição Federal de 1988, todavia, nem por isso deixa de assim ser considerado.

Para a utilização do direito tributário como ferramenta de proteção ao meio ambiente, faz-se necessária a sua devida harmonização com o direito ambiental, a fim de que possa ser instrumento de implementação de políticas públicas ambientais, na busca do desenvolvimento sustentável, sem que isso represente a violação dos direitos e garantias fundamentais dos contribuintes (Freitas, 2005, p. 23). 
Para Oliveira e Périllier (2009, p. 115), na instituição de tributo ou na majoração de tributo existente, não se pode deixar de levar em conta a necessidade de se buscar o desenvolvimento sustentável:

Já que é dever da Administração Pública a defesa de um meio ambiente ecologicamente equilibrado, sendo que a extrafiscalidade se mostra um dos mais eficazes instrumentos de 'incentivo' a determinadas atitudes dos administrados, seja pelo que chamamos de 'tributação punitiva', seja pela 'tributação premiativa'.

Por mais que, em princípio, desenvolvimento e sustentabilidade possam parecer expressões antagônicas, é imprescindível que sejam elas conciliadas, eis que, atualmente, são expressões interdependentes.

Freitas (2011, p. 65) ressalta que:

Desenvolvimento e sustentabilidade não são palavras absolutamente harmônicas, assim, o termo 'desenvolvimento' vem do campo da economia; não de qualquer economia, mas, do tipo imperante, cujo objetivo é a acumulação de bens e serviços de forma crescente e linear mesmo à custa de iniquidade e depredação ecológica.

A sustentabilidade provém do campo da ecologia e da biologia, sendo assim, a inclusão de todos no processo de interretrorelação que caracteriza todos os seres do ecossistema. A sustentabilidade afirma o equilíbrio dinâmico que permite a todos participarem e se verem incluídos no processo global. Tarde, mas, espera-se que a tempo, percebeu o homem que era imprescindível reagir a tal estado de coisas, daí o surgimento da tentativa de ligar os interesses, desenvolvimento e proteção ao meio ambiente, fazendo com que a utilização dos recursos naturais fosse feita como critério, de modo a preservá-los e isto é o que se convencionou chamar de desenvolvimento sustentável (Freitas, 2005, p. 231).

Mais do que encontrar um ponto de equilíbrio entre tais elementos, desenvolvimento e sustentabilidade - que pressupõe a proteção ao meio ambiente -, deve-se uni-los, a ponto de não se poder vislumbrar desenvolvimento que não seja sustentável, ou seja, só se permite o desenvolvimento que seja sustentável. O ideal é que se tome o conceito 'desenvolvimento sustentável' como sendo uma expressão muito redundante, já que o desenvolvimento deve pressupor a sustentabilidade (Ricci, 2015, p. 70). 


\section{CONCLUSÃO}

A Constituição Federal de 1988 trouxe inovações na área do Direito Ambiental, abrindo novos espaços para as ações de proteção ao meio ambiente e, no que diz respeito aos direitos e garantias individuais, à organização do Estado, à tributação, e, ainda à ordem econômica e social do país. A Constituição Federal, porém, não fixou nenhum tributo ambiental específico, embora, acaba por possibilitar no seu texto, condições nas espécies tributárias já existentes, para fixar mecanismos e instrumentos de tributação, enfocando-se o meio ambiente para efeito de preservação a ele dirigida.

Entende-se que não existe anseio, portanto, de se instituir novos tributos, e sim, distribuir de forma mais adequada os recursos arrecadados previstos no Sistema Tributário Nacional em vigor. A arrecadação deveria ser empregada na implementação de políticas públicas em todos os níveis de governo, para propiciar melhores condições para compatibilizar o direito ao desenvolvimento com o direito à proteção do meio ambiente, afiançados constitucionalmente.

É necessário que o meio ambiente seja preservado, não por meio de uma tributação acentuada e, sim, por meio de estímulos ou benefícios, dentre eles, podese destacar os projetos que contemplam planejamentos ambientais que tenha por intuito a preservação e recuperação do meio ambiente degradado. Seja qual for a proposta de instituição da tributação ambiental, a sua regulamentação deverá de ser analisada e discutida em profundidade, estudando-se de forma detalhada os aspectos econômicos e ambientais relativos, de maneira que a tributação ambiental seja realmente eficaz e produza os benefícios sociais esperados.

No que diz respeito as isenções, somente serão constitucionais as que tiverem por intuito desenvolver o equilíbrio do desenvolvimento sócio econômico entre as diferentes regiões do país, levando-se em consideração também que os tributos devem ser uniformes em todo o território nacional. As políticas públicas são bem-vindas, porém, toda a sociedade é responsável pelo desenvolvimento e pelas próprias políticas, assim, se estas não estiverem unidas a outros movimentos ou posturas da própria comunidade, não haverá efetivação das políticas estabelecidas. Por fim, para a qualidade de vida e o desenvolvimento sustentável, é vital que um aglomerado de informações seja efetivamente tratado. 
O artigo 151 da Constituição Federal de 1988 coíbe a instituição de tributo que não seja uniforme em todo território nacional, acatando a concessão de incentivos fiscais voltados a promover o equilíbrio do desenvolvimento sócioeconômico entre as diversas regiões do país. De similar porte, tem-se que qualquer subsídio ou isenção, redução de base de cálculo, concessão de crédito presumido, anistia ou remissão que são relacionados aos tributos, apenas, poderá ser concedido através de lei específica (art. 150 - $\S 6^{\circ}$ da CF).

Já o art. 175 do Código Tributário Nacional ressalta que a isenção é uma forma de exclusão do crédito tributário, em conjunto com a anistia, dentre outros diversos itens. Com estes institutos que englobam a extrafiscalidade, os entes tributantes poderão motivar os contribuintes a realizar algo que a ordem pública considera conveniente ou oportuno de anseio ambiental para a coletividade. Por fim, a extrafiscalidade se manifesta através dos desestímulos fiscais que estimulam contribuintes a não acatarem condutas, mesmo lícitas são havidas por impróprias sob o aspecto político, econômico e social.

\section{REFERÊNCIAS}

BERTI, Anélio; BERTI, Adriana Costa Pereira. Planejamento tributário fácil. Curitiba: Juruá, 2016.

BORGES, José Souto Maior. A lei de responsabilidade fiscal (LRF) e sua inaplicabilidade a incentivos financeiros estaduais. Revista Dialética de Direito Tributário. São Paulo: Dialética, n. 63, p. 81-99, dez. 2000.

. Introdução ao direito financeiro. São Paulo: Max Limonad, 1998.

. Teoria geral da isenção tributária. 3.ed. São Paulo: Malheiros, 2007.

BRAGA, Guilherme Doin; CASTRO, Katiana de. Apontamentos gerais do direito tributário ambiental. In: ORLANDO, Breno Ladeira Kingma et al. (Org.). Direito tributário ambiental. 2. tir.. Rio de Janeiro: Lumen Juris, 2009.

BRASIL. Código Tributário Nacional: Lei 5.172, de 25 de outubro de 1966. 2.ed. São Paulo: Saraiva, 1997.

CARVALHO, Cristiano. Teoria da decisão tributária. São Paulo: Saraiva, 2013. 
CARVALHO, Paulo Barros de. A Regra Matriz do ICM. São Paulo, 1981. Tese (Docência em Direito Tributário) - Pontifícia Universidade Católica de São Paulo.

. Curso de Direito Tributário. 26.ed. São Paulo: Saraiva, 2014.

CATÃO, Marcos André Vinhais. Regime jurídico dos incentivos fiscais. Rio de Janeiro: Renovar, 2004.

CORREIA NETO, Celso de Barros. O avesso do tributo. São Paulo: Almedina, 2014.

DERANI, Cristiane. Aplicação dos princípios do direito ambiental para o desenvolvimento sustentável. In: TÔRRES, Heleno Taveira (Org.). Direito tributário ambiental. São Paulo: Malheiros, 2005.

Direito ambiental econômico. 3.ed. São Paulo: Saraiva, 2008.

FERRAZ, Roberto. Tributação ambientalmente orientada e as espécies tributárias no Brasil. In: TÔRRES, Heleno Taveira (Org.). Direito tributário ambiental. São Paulo: Malheiros, 2005.

FABRETTI, Láudio Camargo. Código Tributário Nacional Comentado. 5.ed. São Paulo: Atlas, 2005.

FERREIRA, Ivete Senise. Tutela penal do patrimônio cultura. São Paulo, Revista dos Tribunais, 1995, v. 3.

FIORILLO, Celso Antonio. Manual de direito ambiental e legislação aplicável. 2.ed. São Paulo: Max Limonad, 1999.

FREITAS, Juarez. Sustentabilidade: direito ao futuro. Belo Horizonte: Fórum, 2011.

FREITAS, Vladimir Passos de. A Constituição Federal e a efetividade das normas ambientais. 3.ed. São Paulo: Revista dos Tribunais, 2005.

GRUPENMACHER, Betina Treiger. Das exonerações tributárias: incentivos e benefícios fiscais. In: GRUPENMACHER, Betina Treiger et al. Novos horizontes da tributação: um diálogo luso-brasileiro. Lisboa: Almedina, 2012.

HARADA, Kiyoshi. Direito financeiro e tributário. 14.ed. São Paulo: Atlas, 2005.

JARDIM, Eduardo Marcial Ferreira. Dicionário Jurídico. São Paulo: Dialética, 2005.

LEITE, José Rubens Morato; CANOTILHO, José Joaquim Gomes. Direito Constitucional Ambiental brasileiro. São Paulo: Saraiva, 2007.

MACHADO, Hugo de Brito. Curso de direito tributário. 25.ed. rev. atual. e ampl. São Paulo: Malheiros, 2004.

NABAIS, José Casalta. Direito fiscal. 7.ed. Coimbra: Almedina, 2012. 
OLIVEIRA, Gustavo Goiabeira de; PÉRILLIER, Eduardo Barros Miranda. A extrafiscalidade como instrumento de controle ambiental. In: ORLANDO, Breno Ladeira Kingma et al. (Orgs.). Direito tributário ambiental. 2.tir. Rio de Janeiro: Lumen Juris, 2009. p. 115.

OLIVEIRA JÚNIOR, Afrânio Menezes de. Incentivos fiscais no âmbito do ICMS: regramento constitucional, falhas jurídico-legislativas, federalismo e guerra fiscal. Curitiba: Juruá, 2016.

PIRES, Adilson Rodrigues. Ligeiras reflexões sobre a questão dos incentivos fiscais no Brasil. In: MARTINS, Ives Gandra da Silva; ELALI, André; PEIXOTO, Marcelo Magalhães. Incentivos fiscais: questões pontuais nas esferas federal, estadual e municipal. São Paulo: MP, 2007.

PEIXOTO, Daniel Monteiro. Guerra fiscal via ICMS: controle dos incentivos fiscais e os casos "FUNDAP" e "Comunicado CAT 36/04". In: MARTINS, Ives Gandra da Silva; ELALI, André; PEIXOTO, Marcelo Magalhães. Incentivos fiscais: questões pontuais nas esferas federal, estadual e municipal. São Paulo: MP, 2007.

$\mathrm{RICCl}$, Henrique Cavalheiro. Direito tributário ambiental e isonomia fiscal: extrafiscalidade, limitações, capacidade contributiva, proporcionalidade e seletividade. Curitiba: Juruá, 2015.

ROCHA, José Afonso da. Direito ambiental e meio ambiente do trabalho. São Paulo: LTr, 2001.

SALIBA, Ricardo Berzosa. Fundamentos do direito tributário ambiental. São Paulo: Quartier Latin, 2005.

SCHOUERI, Luís Eduardo. Normas tributárias indutoras e intervenção econômica. Rio de Janeiro: Forense, 2005.

SILVA, José Afonso. Direito ambiental constitucional. 10.ed. atual. São Paulo: Malheiros, 2013.

SIRVINSKAS, Luiz Paulo. Manual de direito ambiental. 13.ed. 2.tir. São Paulo: Saraiva, 2015.

YOUNG, Lúcia Helena Briski. Planejamento tributário. 8.ed. Curitiba: Juruá, 2014. 